\title{
ETHNOBOTANICAL, PHYTOCHEMICAL, AND PHARMACOLOGICAL PROPERTIES OF NEPENTHES SPECIES: A REVIEW
}

\author{
SHUAIBU BABAJI SANUSI, MOHD FADZELLY ABU BAKAR*, MARYATI MOHAMED, SITI FATIMAH SABRAN, \\ MUHAMMAD MURTALA MAINASARA
}

Centre of Research for Sustainable Uses of Natural Resources (CoR-SUNR), Faculty of Science, Technology and Human Development, Universiti Tun Hussein Onn Malaysia (UTHM), 86400 Parit Raja, Batu Pahat, Johor, Malaysia. Email: fadzelly@uthm.edu.my

Received: 18 May 2017, Revised and Accepted: 17 July 2017

\begin{abstract}
The genus Nepenthes (Nepenthaceae) has been utilized in folk medicine for a long time in India and Southeast Asia countries. They are used in the treatment of leprosy, cholera, night blindness, gastrointestinal discomfort, dysentery, stomachache, and bed-wetting among others. This review highlights the ethnobotanical uses, phytochemicals, and pharmacological activities of both crude extracts and pure bioactive compounds of Nepenthes spp. The phytochemical compounds isolated from Nepenthes species include flavonoids, terpenoids, tannins, alkaloids, and steroids among other phytochemicals. A wide range of pharmacological activities was exhibited by the crude extracts and pure bioactive components such as antibacterial, antifungal, antimalarial antioxidant, antidiabetic, antiosteoporotic, anti-inflammatory, cytotoxicity, and hypolipidemic activities. This review revealed that many active compounds are present in Nepenthes spp. However, many pharmacological screenings such as anticancer, antiviral, wound healing, antihelminthic, antidiarrheal properties, among others have not been carried out yet. Therefore, more biological investigations and phytochemical screenings are required to fully explore the genus Nepenthes which may lead to development of new therapeutic agents.
\end{abstract}

Keywords: Nepenthes species, Ethnobotanical, Phytochemistry, Pharmacological activities.

(C) 2017 The Authors. Published by Innovare Academic Sciences Pvt Ltd. This is an open access article under the CC BY license (http://creativecommons. org/licenses/by/4. 0/) DOI: http://dx.doi.org/10.22159/ajpcr.2017.v10i11.20050

\section{INTRODUCTION}

Natural products have been used as alternative treatments for various diseases due to their reasonable efficacy and low toxicity [1]. Biologically active compounds from natural resources have always been of great interest to scientists working on different diseases [2]. Plants and plant-based medicines are since been used as the basis of many modern pharmaceuticals used today for the treatment of various ailments [3-6]. Despite the fact that the modern medicines are more accepted worldwide, folk medicines are still being used either as complementary or alternative medicines, especially due to their good therapeutic effects and less side effects [7,8]. The World Health Organization reported that more than $80 \%$ of global population from both developing and developed countries uses their indigenous plants for basic health care to treat various health issues [9-11]. Nepenthes species is from the family of Nepenthaceae, widely known as pitcher plant that is carnivorous in nature. It is the only genus in the family of Nepenthaceae from the order Nepenthales which produces unique pitcher for trapping and digestion of insect pray to acquire nutrients at habitats that are deprived of nitrogen [12]. The stem of pitcher plant is a climber, subshrubs, or herbs. The pitcher itself is as a result of modification of the leaf blade $[13,14]$. Nepenthes species consists of over 100 species distributed within southern China, northern Australia, New Caledonia, and western Pacific islands with Indonesia, Malaysia, Philippines, India, and Brunei Darussalam considered world's diversity centers of Nepenthes $[13,15,16]$. Nepenthes spp. have been utilized in traditional medicine system to treat and control different ailments including gastrointestinal discomfort, such as dysentery, stomachache, and bed-wetting among others [17]. A wide range of phytochemicals were identified and isolated from different species of Nepenthes [18-22]. The previous researches showed that Nepenthes spp. exhibited many pharmacological actions, including antibacterial, antifungal, antimalarial antioxidant, antidiabetic, and hypolipidemic among others [19-21,23]. The previous studies as mentioned above indicated that Nepenthes spp. possesses a lot of ethnobotanical, phytochemical, and pharmacological properties; however, no previous study attempted to summarize these findings. Thus, the objective of this review is to highlight the ethnobotanical use, phytochemistry and the pharmacological activities of both crude extracts and pure bioactive compounds of Nepenthes spp.

\section{ETHNOBOTANICAL USE}

Nepenthes species have been used in traditional medicines to treat numerous illnesses. It has been reported that the Northeast Indian herbalist prescribed the fluid contain from an unopened pitcher of Nepenthes khasiana for the treatment of diabetes mellitus [13]. In addition, the fluid from unopened pitcher of $N$. khasiana is prescribed to cure night blindness, conjunctivitis, ear troubles, and gynecological problems. Khasi people consume the liquid in the morning as a digestive tonic. The grinded powder of the $N$. khasiana pitcher is used to treat cholera. Garo traditional medical practitioners use $N$. khasiana to treat leprosy by applying a fine paste of the pitcher [24]. The people of Dayak Serebuang used the fluid from unopened pitcher of Nepenthes to cure stomachache and cough [16]. The root of Nepenthes is used traditionally in the treatment of bed-wetting dysentery and stomachache [17]. Nepenthes ampullaria and Nepenthes gracilis are the two most common species used in folk medicine, where the liquid contain of an unopened pitcher are administered to regulate the menstrual cycle, ease child birth, relieve asthma, treat eye inflammation, and act as a stamina booster [21]. Root decoction of $N$. ampularia was understood to be employed in asthma treatment by Orang Asli from Jakun community in Endau Romping, Johor, Malaysia [25]. The blended leaves of some Nepenthes spp. have been used as an astringent in Malaysia [26]. In Malaysia, the decoction of stem of $N$. ampullaria has been consumed to treat malaria [27]. In Vietnam, Nepenthes mirabilis is used in the treatment of gastric ulcer, jaundice, high blood pressure, ureteral stones, and hepatitis by traditional medical practitioner [28].

\section{PHYTOCHEMISTRY}

Sterols and triterpenes including campesterol, isofuctosterol, stigmasterol, sitosterol, $\alpha$-amyrin and $\beta$-amyrin were identified in free form in Nepenthes albomarginata. While in esterified form, campesterol, 
stigmasterol, sitosterol, isofucosterol, obtusifoliol, cycloeucalenol, citrostadieno1, cycloartenol, and 24-methylenecycloartanol were identified in N. albomarginata [29]. Plumbagin, droserone, hydroxydroserone, and other four new quinones including nepenthone-A, nepenthone- $B$, nepenthone- $C$, and nepenthone-E were obtained from Nepenthes rafflesiana roots, while the fifth quinone, nepenthone-D was identified [30]. Likhitwitayawuid et al. isolated 2-methylnaphthazarin, droserone, isoshinanolone, octadecylcaffeate, and plumbagin from the roots of Nepenthes thorelii [20]. A phytochemical screening of different Nepenthes spp. (Nepenthes burbidgeae, Nepenthes tentaculata, N. mirabilis, Nepenthes muluensis, Nepenthes rajah, and Nepenthes gracilis) leaves showed that quercetin is detected in $N$. burbidgea, $N$. mirabilis, $N$. muluensis, N. rajah, and $N$. gracilis. Except in $N$. gracilis, Kaempferol was identified in all of the studied pitcher plants. Leucoanthocyanins such as cyanidin was present in N. gracilis, N. mirabilis, and N. rajah [22]. The compounds epishinanolone, isoshinanolone, kaempferol, plumbagin, quercetin, and shinanolone were successfully isolated from the leaves of $N$. gracilis by Aung et al. [26]. A study by Shin et al. resulted in the identification and purification of plumbagin from the extract Nepenthes ventricosa $\mathrm{x}$ maxima leaves [27]. A liquid from the pitcher of $N$. khasiana was found to contained 5-0-methyldroserone and droserone [31]. Plumbagin was isolated from the fresh leaves of $N$. gracilis [32]. A phytochemical analysis of pitcher and leaf extract of $N$. khasiana Hook showed the existence of flavonoids, glycoside, tannins, alkaloids, phytosterols, and saponins $[13,23,24] . \quad 13$ active compounds including nepenthosides A, nepenthosides $B$, leonuriside $A$, koaburaside, 4-hydroxy-2,6-dimethoxyphenyl 6'-0-vanilloyl- $\beta$-D-glucopyranoside, (-)-heimiol A, phenylethyl- $\beta$-D-glucopyranoside, icariside $\mathrm{D}_{1}$, rutinoside, syringaresinol, syringaresinol-4'-O- $\beta$-D-glucopyranoside, pinoresinol4-0- $\beta$-D- glucopyranoside and lupeone were obtained from the leaves and branches extract of $N$. mirabilis [28]. Phytochemical such as alkaloids, flavonoids, tannins, anthraquinones, phlobatannins steroids, and terpenoids were detected in the screening of Nepenthes bicalcarata Hook. F. [21]. Two novel naphthoquinones, namely, nepenthones $\mathrm{F}$ and nepenthones $\mathrm{G}$ as well as five famous naphthoquinones including droserone, plumbagin, 3-methoxy-7-methyljuglone, 2-methoxy-7methyljuglone, nepenthone $\mathrm{C}$, and a well-known acetogenictetralone; cis-isoshinanolone were obtained from branches and leaves extracts of N. mirabilis [19]. In addition, from the leaves and branches extracts of $N$. mirabilis, five known flavonoids, namely, quercetin, quercetin 3-0- $\beta$-D-glucuronide, quercitrin, kaempferol-3-O- $\alpha$-L-rhamnoside, and (-)-epicatechin were also isolated [19].26 biologically active compounds were isolated from $N$. mirabilis (Lour.) Rafarin, and these are identified as nepenthone $\mathrm{F}$, nepenthone $\mathrm{G}$, nepenthoside $\mathrm{A}$, nepenthoside $\mathrm{B}$, cisisoshinanolone, droserone, plumbagin, 3-methoxy-7-methyljuglone, 2-methoxy-7-methyljuglone, nepenthone $\mathrm{C},(-)$-heimiol A, 4-hydroxy2,6-dimethoxyphenyl 6'-O-vanilloyl- $\beta$-D-glucopyranoside, leonuriside A, koaburaside, syringaresinol, syringaresinol-4'- $\beta$-D-glucopyranoside, pinoresinol-4-0- $\beta$-D-glucopyranoside, lupeone, phenylethyl- $\beta$ D-glucopyranoside, icariside $D_{1}$, phenethylrutinoside, quercetin, quercitrin, kaempferol-3-0- $\alpha$-L-rhamnoside, quercetin 3-O- $\beta$-Dglucuronide, and (-)-epicatechin [33].

\section{PHARMACOLOGICAL ACTIVITIES}

\section{Antioxidant}

The methanolic leaf extract of $N$. khasiana displayed strong antioxidant properties with the half maximal inhibitory concentration $\left(\mathrm{IC}_{50}\right.$ ) of $23.33 \pm 0.441,62.75 \pm 0.713$, and $38.38 \pm 0.425 \mu \mathrm{g} / \mathrm{ml}$ in 2,2-diphenyl1-picrylhydrazyl (DPPH), superoxide anion, and hydroxyl radical scavenging activity, respectively [24]. The methanol extract of $N$. bicalcarata leaf was investigated for it scavenging activity using DPPH and 2,2'-azino-bis(3-ethylbenzothiazoline-6-sulphonic acid) (ABTS) assays which Trolox and butylated hydroxytoluene (BHT) were used as the standards in the respective assays. The leaf extract was found to be more active than standard BHT in the DPPH assay, whereas in the ABTS assay, it was the least active when compared with both standards as indicated by its higher $\mathrm{IC}_{50}$ value [21]. Antioxidant properties of the pure compounds isolated from branches and leaves of $N$. mirabilis were studied for their peroxyl radical scavenging and reducing capabilities. Compounds such as nepenthones F, droserone, nepenthone C, cisisoshinanolone, quercetin, quercetin 3-0- $\beta$-D-glucuronide, quercitrin, kaempferol-3-0- $\alpha$-L-rhamnoside, and (-)-epicatechin were found to exhibited strong peroxyl radical scavenging activities in a dosedependent manner at 1.0 and $10.0 \mu \mathrm{M}$ concentrations [19].

\section{Antidiabetic}

A study was conducted on the hypolipidemic and hypoglycemic potential of $N$. khasiana Hook pitcher extract in insulin resistance and dexamethasone-induced hyperlipidemia in laboratory rats. At a dosage level of 250 and $500 \mathrm{mg} / \mathrm{kg}$, methanolic extract of $N$. khasiana pitcher actively prevented the increase in the level of cholesterol, glucose, triglyceride, low density lipoprotein with progressive decreased in both high density lipoprotein, and body weight triggered by dexamethasone on tested rats [23]. Hypoglycemic property of methanolic leaf extract of $N$. bicalcarata was reported in the alloxan diabetic induced rats. A dose of $300 \mathrm{mg} / \mathrm{kg}$ body weight showed a significant decrease in blood glucose level in a time-dependent manner [21].

\section{Antimalarial}

Compounds plumbagin, 2- methylnaphthazarin, droserone, and isoshinanolone obtained from the ethanolic extract of $N$. thorelii roots was evaluated against Plasmodium falciparum for antimalarial activity, all the compound exhibited potent activity, especially plumbagin at $0.27 \mu \mathrm{M}$ where $50 \%$ inhibition of response was shown $\left(\mathrm{lC}_{50}=0.27 \mu \mathrm{m}\right)[20]$.

\section{Antibacterial}

The whole plant methanolic crude extract of $N$. mirabilis was found to be active against Staphylococcus aureus as assessed using disc diffusion assay [34]. The methanolic extract of $N$. bicalcarata leaf displayed antibacterial activities against gram-positive bacteria Bacillus subtilis, Bacillus spizizenii and S. aureus with minimum inhibitory concentration (MIC) values ranging from 256 to $1024 \mu \mathrm{g} / \mathrm{ml}$ [21]. Silver nanoparticles synthesized from the Nepenthes spp. exhibited a strong inhibitory activity against $S$. aureus, E. coli and S. enterica [35].

\section{Antifungal}

The hexane extract from $N$. gracilis showed antifungal activity with the MIC and minimum fungicidal concentration of $20 \mu \mathrm{g} / \mathrm{ml}$ against Candida albicans, Issatchenkia orientalis, and Trichophyton mentagrophytes. The compound plumbagin isolated showed strong antifungal activity with the MIC values between 2 and $31 \mu \mathrm{g} / \mathrm{ml}$ against all of the tested fungi [32]. The pitcher liquid extract of $N$. khasiana contained droserone, 5-0-methyldroserone, and purified naphthoquinones which exhibited antifungal activities when tested against Aspergillus sp. and Candida sp. [31]. The antifungal activity of 3:1 droserone: medroserone mixture tested against C. albicans, Candida glabrata, Candida krusei, and Aspergillus fumigatus showed MICs of 63, 125, 63, and $250 \mu \mathrm{g} / \mathrm{ml}$, respectively [31]. The crude hexane extract of Nepenthes ventricosa $\mathrm{x}$ maxima leaf showed strong antifungal activity against plant fungal pathogens screened, namely, Alternaria alternata, Aspergillus niger, Bipolaris oryzae, Fusarium oxysporum, Phytophthora capsici, Rhizopus stolonifera var. stolonifera, Rhizoetonia solani, Sclerotinia sclerotiorum, of which R. solani was the most sensitive [27]. A bioactive compound, plumbagin identified, and purified from the leaves extract of $N$. ventrieosa x maxima showed MIC values between 4.8 and $56.6 \mu \mathrm{g} / \mathrm{ml}$ when screened for antifungal activities against $A$. niger, A. alternata, F. oxysporum, P. capsid, R. solani, R. stolonifera, B. oryzae, and Sclerotinia scierotiorum [18]. The methanol extract of $N$. bicalcarata leaf exhibited good activity against non-filamentous fungi Saccharomyces cerevisiae and C. albicans with MIC ranged from 256 to $1024 \mu \mathrm{g} / \mathrm{ml}$ [21].

\section{CYTOTOXICITY}

The brine shrimp lethality toxicity at $50 \%\left(\mathrm{LC}_{50}\right)$ methanolic leaf extract of $N$. bicalcarata was determined through probit analysis, and it was estimated to be $73.3 \mu \mathrm{g} / \mathrm{ml}$ which may be considered as mildly 
toxic according to Meyer et al. said that high toxicity is indicated by a $\mathrm{LC}_{50}<30 \mu \mathrm{g} / \mathrm{ml}[21,36]$. The viability of LLC-MK2 cells treated with different plumbagin concentrations were measured by NRU assay. Moreover, a $50 \%$ cytotoxicity concentration of plumbagin at $0.60 \mu \mathrm{g} / \mathrm{ml}$ was observed [32]. Acute cytotoxicity study showed that the N. khasiana methanolic extract of leaf neither demonstrated any toxicity nor mortality at a $3000 \mathrm{mg} / \mathrm{kg}$ bw dose level in rats [13].

\section{HEPATOPROTECTIVE}

Hepatoprotective activity of $N$. khasiana against alcoholic induced liver damage in adult Wistar albino rats was reported. The administration of methanolic extract reversed the damage effect due to alcohol on liver as showed from histopathological investigations of the liver. Thus, exhibited a potent hepatoprotective effect [24].

\section{ANTIOSTEOPOROTIC}

The inhibitory effects of compounds isolated from branches and leaves methanolic extract of $N$. mirabilis on osteoclast differentiation were examined by measuring the suppression of excessive bone resorption by osteoclasts. These compounds including plumbagin, 2-methoxy7-methyljuglone, cis-isoshinanolone, quercetin 3-0- $\beta$-D-glucuronide, and kaempferol-3-0- $\alpha$-L-rhamnoside significantly decreased TRAP activity in multinucleated osteoclast cells at concentration of $10.0 \mu \mathrm{M}$ compared with positive control (genistein). Consequently, the findings demonstrated that $N$. mirabilis is a good source of biologically active compound for the osteoporosis treatment [19].

\section{ANTI-INFLAMMATORY}

Some compounds isolated from branches and leaves methanolic extract of $N$. mirabilis showed anti-inflammatory activities. 2-methoxy7-methyljuglone inhibited the production of interleukin (IL-12) p40, IL-6, and tumor necrosis factor $(\mathrm{TNF}-\alpha)\left(\mathrm{IC}_{50}=0.17 \pm 0.02,0.46 \pm 0.01\right.$, and $8.28 \pm 0.21 \mu \mathrm{M}$, respectively). The active compound, nepenthoside B exhibited strong inhibition of IL-12 p40, and IL-6 production $\left(\mathrm{IC}_{50}=1.17 \pm 0.01\right.$ and $\left.2.15 \pm 0.04 \mu \mathrm{M}\right)$. Likewise, the inhibition of IL- 12 p40 by naphthalene derivatives (nepenthoside $A$, nepenthoside $B$, nepenthone $\mathrm{C}$, nepenthone $\mathrm{F}$, nepenthone $\mathrm{G}$, cis-isoshinanolone, droserone, 2-methoxy-7-methyljuglone, and plumbagin), phenolic compounds ((-)-heimiol A, 4-hydroxy-2,6-dimethoxyphenyl 6'0 - vanilloyl- $\beta$-D-glucopyranoside, koaburaside, leonuriside $A$, and syringaresinol), lupeone, and flavonoids (quercetin, (-)-epicatechin, quercetin 3-0- $\beta$-D- and glucuronide) was more effective than positive control. However, these bioactive compounds showed no or little inhibitory properties on TNF- $\alpha$ production in lipopolysaccharidestimulated bone marrow-derived dendritic cells [33].

\section{CONCLUSION}

This study revealed that Nepenthes spp. is an essential medicinal plant with broad pharmacological spectrum. Many species of Nepenthes show the presence of various phytochemical constituents responsible for various pharmacological and ethnomedicinal properties. Further study on the available information is crucial in developing novel clinical therapeutics out of Nepenthes spp. This review will proffer a remarkable opportunity for future research as it compiled the information related to various aspects of this medicinal plant genus.

\section{ACKNOWLEDGMENTS}

The authors are very grateful to Universiti Tun Hussein Onn Malaysia (UTHM) for providing the research grant (UTHM Grant Contract, Vot No: U555 and IGSP, Vot No: U673) that supported the study.

\section{REFERENCES}

1. Ijaz H, Tulain UR, Qureshi J, Danish Z, Musayab S, Akhtar MF, et al. Review: Nigella sativa (prophetic medicine): A review. Pak J Pharm Sci 2017;30(1):229-34.

2. Krishnakumar S, Bai VD, Rajan RA. Evaluation of bioactive metabolites from halophilic microalgae Dunaliella salina by GC - MS analysis. Int J Pharm Pharm Sci 2013;5(4):296-303.

3. Antony E, Sathiavelu M, Arunachalam S. Synthesis of silver nanoparticles from the medicinal plant Bauhinia acuminata and Biophytum sensitivum-a comparative study of its biological activities with plant extract. Int J Appl Pharm 2017;9(1):1-8.

4. Sanusi SB, Bakar MF, Mohamed M, Sabran SF, Mainasara MM. Southeast Asian medicinal plants as a potential source of anti-tuberculosis agent. Evid Based Complement Altern Med 2017;2017: Article ID: 7185649, 39.

5. Gajalakshmi S, Vijayalakshmi S, Rajeswari VD. Phytochemical and pharmacological properties of Annona muricata: A review. Int J Pharm Pharm Sci 2012;4(2):13-6.

6. Himaja N, Shama SN. Herbal wealth for hepatotoxicity: A review. Asian J Pharm Clin Res 2015;8(1):3-9.

7. Divya BJ, Suman B, Venkataswamy M, Thyagaraju K. A study on phytochemicals, functional groups and mineral composition of Allium sativum (garlic) cloves. Int J Curr Pharm Res 2017;9(3):40-3.

8. Monton C, Suksaeree J, Pathompak P. Can makjong (Scaphium macropodum) powder formed gel in effervescent blend? Int J Pharm Pharm Sci 2014;6(6):610-2.

9. Garza BAA, Arroyo JL, González GG, González EG, González EG, de Torres NW, et al. Anti-fungal and anti-mycobacterial activity of plants of Nuevo Leon, Mexico. Pak J Pharm Sci 2017;30(1):17-21.

10. Shad AA, Asmat S, Bakht J, Ala Uddin A. Screening of Aerva javanica and Linum ustitatissimum for their anti-diabetic and anti-oxidant activity. Pak J Pharm Sci 2017;30(1):67-73.

11. Rahmani AH, Aly SM. Nigella Sativa and its active constituents thymoquinone shows pivotal role in the diseases prevention and treatment. Asian J Pharm Clin Res 2015;8(1):48-53.

12. Wan-Nor-AdibahWan Z, Loke KK, Zulkapli MM, Salleh IM, Goh HH, Noor NM. RNA-seq analysis of Nepenthes ampullaria. Int J Plant Sci 2016;164(4):635-9.

13. Shil D, Mohanty JP, Saleem TS, Debnath J, Uriah T. Anti-diabetic activity of leaf extract of Nepenthes khasiana hook on dexamethasone induced diabetic rats. J Pharm Chem Biol Sci 2014;1(1):6-11.

14. Buch F, Rott M, Rottloff S, Paetz C, Hilke I, Raessler M, et al. Secreted pitfall-trap fluid of carnivorous Nepenthes plants is unsuitable for microbial growth. Ann Bot 2013;111(3):375-83.

15. Moran JA, Clarke CM. The carnivorous syndrome in Nepenthes pitcher plants: current state of knowledge and potential future directions. Plant Signal Behav 2010;5(6):644-8

16. Setiawan H, Hakim L, Batoro J. Ethnobotany of Nepenthes spp. In dayak Seberuang people, west Kalimantan, Indonesia. J Biodivers Environ Sci 2015;7(6):275-84.

17. Schwallier R, de Boer HJ, Visser N, van Vugt RR, Gravendeel B. Traps as treats: A traditional sticky rice snack persisting in rapidly changing Asian kitchens. J Ethnobiol Ethnomed 2015;11:24.

18. Shin KS, Lee SK, Cha BJ. Antifungal activity of plumbagin purified from leaves of Nepenthes ventricosa x maxima against phytopathogenic fungi. Plant Pathol J 2007;23(2):113-5.

19. Van Thanh N, Thao NP, Huong PT, Lee SH, Jang HD, Cuong NX, et al. Naphthoquinone and flavonoid constituents from the carnivorous plant Nepenthes mirabilis and their anti-osteoporotic and antioxidant activities. Phytochem Lett 2015;11:254-9.

20. Likhitwitayawuid K, Kaewamatawong R, Ruangrungsi N, Krungkrai J. Antimalarial naphthoquinones from Nepenthes thorelii. Planta Med 1998;64(3):237-41.

21. Ismail NA, Kamariah AS, Lim LB, Ahmad N. Phytochemical and pharmacological evaluation of methanolic extracts of the leaves of Nepenthes bicalcarata Hook. F. Int J Pharmacogn Phytochem Res 2015;7(6):1127-38

22. Adam JH, Omar R, Wilcock CC. Phytochemical screening of flavonoids in three hybrids of Nepenthes (Nepenthaceae) and their putative parental species from Sarawak and Sabah. J Biol Sci 2002;2(9):623-5.

23. Shil D, Mohanty JP, Das T, Bhuyan NR, Uriah T, MohamedSaleem TS. Protective role of pitcher of Nepenthes khasiana Hook against dexamethazone induced hyperlipidemia and insulin resistance in rat. Int J Res Pharm Sci 2010;1(2):195-8.

24. Tiewlasubon U, Mrityunjaya BP, Sivaiah K. In vitro antioxidant and hepatoprotective potential of Nepenthes Khasiana Hook. F against ethanol-induced. J Pharm Res 2015;14(4):81-9.

25. Sabran SF, Mohamed M, Abu Bakar MF. Ethnomedical knowledge of plants used for the treatment of tuberculosis in Johor, Malaysia. Evid Based Complement Alternat Med 2016;2016:2850845.

26. Aung HH, Chia LS, Goh NK, Chia TF, Ahmed AA, Pare PW, et al. Phenolic constituents from the leaves of the carnivorous plant Nepenthes gracilis. Fitoterapia 2002;73(5):445-7. 
27. Shin KS, Lee S, Cha BJ. Suppression of phytopathogenic fungi by hexane extract of Nepenthes ventricosa $x$ maxima leaf. Fitoterapia 2007;78(7-8):585-6.

28. Thanh NV, Thao NP, Dat le D, Huong PT, Lee SH, Jang HD, et al. Two new naphthalene glucosides and other bioactive compounds from the carnivorous plant Nepenthes mirabilis. Arch Pharm Res 2015;38(10):1774-82.

29. Wan AS, Aexel RT, Ramsey RB, Nicholas HJ. Sterols and triterpenes of the pitcher plant. Phytochemistry 1971;11(1):456-61.

30. Cannon J, Lojanapiwatna V, Raston C, Sinchai W, White A. The quinones of Nepenthes rafflesiana the crystal structure of 2, 5-dihydroxy-3, 8-dimethoxy-7-methylnaphtho-1, 4-quinone (nepenthone-E) and a synthesis of 2, 5-dihydroxy-3-methoxy-7-methylnaphtho-1, 4-quinone (nepenthone-C). Aust J Chem 1980;33(5):1073-93.

31. Eilenberg H, Pnini-Cohen S, Rahamim Y, Sionov E, Segal E, Carmeli S, et al. Induced production of antifungal naphthoquinones in the pitchers of the carnivorous plant Nepenthes khasiana. J Exp Bot 2010;61(3):911-22

32. Gwee PS, Khoo KS, Ong HC, Sit NW. Bioactivity-guided isolation and structural characterization of the antifungal compound, plumbagin, from Nepenthes gracilis. Pharm Biol 2014;52(12):1526-31.

33. Thao NP, Luyen BT, Koo JE, Kim S, Koh YS, Thanh N, et al. In vitro anti-inflammatory components isolated from the carnivorous plant Nepenthes mirabilis (Lour.) Rafarin. Pharm Biol 2015;17:1-7.

34. Wiart C, Mogana S, Khalifah S, Mahan M, Ismail S, Buckle M, et al. Antimicrobial screening of plants used for traditional medicine in the state of Perak, Peninsular Malaysia. Fitoterapia 2004;75(1):68-73.

35. Majeed S, Afzan M. Biosynthesis of silver nanoparticles using Nepenthes spp. and its bactericidal effect. Der Pharm Chem 2016;8(19):279-82.

36. Meyer B, Ferrigni NR, Putnam JE, Jacobsen LB, Nichols DE, McLaughlin JL. Brine shrimp: A convinient general bioassay for active plant consyituents. J Med Plant Res 1982;45(5):31-4. 